\title{
Conceitos de Força Manifestos nas Falas de Professores de Física
}

\section{The Concepts of Force Manifested in the Speech of Physics Professors}

\author{
Dilene Rodrigues Martins ${ }^{1}$ \\ Darcos César Danhoni Neves ${ }^{1}$ \\ iD Daniel Gardelli²
}

\begin{abstract}
'Universidade Estadual de Maringá (UEM), Programa de Pós-Graduação em Educação para a Ciência, e a Matemática, Maringá, PR, Brasil. Autora correspondente: milene.rm1@gmail.com

Universidade Estadual de Maringá (UEM), Departamento de Física, Maringá, PR, Brasil.
\end{abstract}

Resumo: O presente artigo tem por finalidade investigar como o conceito de força é abordado no discurso de professores universitários de Física de uma instituição pública do norte do Paraná, com ênfase em sua dimensão histórica, especialmente entre os séculos XVII e XVIII. Para atender a esse objetivo foram adotados os pressupostos da pesquisa fenomenológica, com o intuito de encontrar indícios de como se deu a construção destes conceitos e, de maneira indireta, entender como e se a História da Física está presente em suas práticas didáticas. Ao fim das análises, pode-se identificar que a versão que é sucintamente difundida na maioria das concepções dos docentes refere-se a uma abordagem essencialmente direcionada à mecânica newtoniana, que suplanta indevidamente as contribuições de seus predecessores e sucessores.

Palavras-chave: Ensino de Física; Ensino superior; História da física; Fenomenologia.

Abstract: The present work aims to investigate the ways how the concept of force is approached in the discourse of Physics college professors from a public institution in the north of Paraná state, by emphasizing its dimension of historical construction, especially regarding the period between the 17th and 18th centuries. To meet this objective, the assumptions of phenomenological research were adopted in order to find evidence of how it gave rise to the construction of concepts and, indirectly, to explain how and whether the History of Physics is present in its didactic practices. At the end of the analyses, one can find that the version that is succinctly disseminated in most of the conceptions held by the professors refers to an approach directed to Newtonian mechanics, which unduly supersedes the contributions of its predecessors and successors.

Keywords: Physics teaching; Higher education; History of physics; Phenomenology.

Recebido em: 06/07/2020

Aprovado em: 29/12/2020 


\section{Introdução}

O conceito de força é um dos principais constructos teóricos a serem ensinados para os estudantes, ainda no Ensino Fundamental. No decorrer de seus estudos, eles o reencontram e o aprofundam, estudam a força gravitacional, a força elástica, a força eletromagnética, a força elétrica etc. Em muitos livros didáticos de Física, a força é o primeiro conceito não matemático explanado. Costuma-se dar ênfase as suas inúmeras aplicações bem-sucedidas e por meio delas comprovar seu status de verdade científica.

Ao voltar os olhos para os critérios elencados para a existência de forças, Ellis (1965) propõe que, quando um sistema está sujeito à ação de uma força, aparentemente, existem dois destes critérios: se, (1), o sistema persistir no que se considera como um estado não natural, ou se, (2), o sistema está mudando no que se entende ser uma forma não natural. Desse modo, infere-se que um sistema é acionado por uma força (ou forças) se o sistema persistir em um estado não natural ou que está mudando de forma não natural. Um sistema é considerado em um estado não natural se considerar que sua continuação nesse estado requer explicação causal (ELLIS, 1965).

De acordo com os critérios adotados pelo autor para a existência de forças, pode-se conceber que as forças que existem na natureza (para explicar os efeitos) têm uma espécie de existência convencional, pois elas existem apenas porque escolhese considerar certas mudanças ou estados como naturais e outros como não naturais (ELLIS, 1965).

Tais discussões, contudo, muitas vezes, encontram-se ausentes, pois tanto nos manuais didáticos quanto na bibliografia especializada são fornecidas, geralmente, poucas informações acerca da natureza do conceito de força em si ou sobre a sua construção histórica, pois subentende-se que se trata de um conceito intuitivo, que possui uma vasta aplicação prática, fácil de ser verificada e testada. Seu caráter problemático é, muitas vezes, ignorado, podendo conduzir erroneamente os estudantes de ciências a entendê-la e tratá-la como entidade mística ou até como qualidades ocultas. Ademais, "[...] não raro e não apenas nos cursos elementares e introdutórios de física, a 'força' é interpretada à maneira animista ou peripatética tradicional, como uma 'tendência' ou um 'esforço para'" (JAMMER, 2011, p. 15-16). Também é possível encontrar afirmações alegando que uma força é capaz de superar outra.

Outrora, com o pensamento antigo, as interpretações animistas e espirituais da realidade física ganharam espaço, servindo de base para que a ciência pré-clássica propusesse a existência de conotações extracientíficas que exerceram influência na interpretação do conceito de força até épocas recentes. Na ciência aristotélicoptolomaica se tinha um sistema de concepções essencialmente geométrico-cinemáticas, já a ciência dos séculos XVII e XVIII pautava-se - porém não de modo exclusivo - nos escritos newtonianos sobre a dinâmica dos corpos. Percebe-se, portanto, que a investigação crítica e histórica do conceito de força se faz necessária para que seja possível compreender o desenvolvimento da ciência moderna.

A explanação do desenvolvimento histórico de cada uma das forças que a física contempla é, no entanto, impossível, tendo em vista que cada uso da expressão força implica um sentido e uma construção histórica diferente. Neste sentido, neste trabalho se optará por abordar os conceitos de força mecânica, em especial no contexto dos séculos XVII e XVIII. 
Ao se estudar o desenvolvimento do conceito de força, é comum esbarrar em obstáculos inerentes ao caráter intrinsicamente impreciso das definições, pois os conceitos científicos só encontram especificação rigorosa mediante uma definição científica exata. Mas essa definição, sob a óptica de um viés histórico, se dá em uma etapa posterior de sua construção. Portanto, "[...] limitar a discussão aos conceitos assim definidos significa ignorar uma parte fundamental de sua história" (JAMMER, 2011, p. 22).

Poincaré (1905 apud NEVES, 2000, p. 543), acerca da noção do conceito de força já escrevia algures:

Mas não preciso de uma definição da força: a ideia de força é uma noção primitiva, irredutível, indefinível. Todos sabemos que coisa ela é, temos uma intuição direta dela. Ela deriva da noção de esforço, que nos é familiar desde a infância. Mas, quando também, tal intuição nos fizesse conhecer a verdadeira natureza da força, ela seria, sobretudo, o fundamento da Mecânica, e, em consequência, inútil. Aquilo que conta não é saber que coisa é a força, mas saber medi-la.

Ao encontro dessa objeção, entende-se que a história do conceito de força não está concluída e nem estará, mesmo após alcançar o patamar de definido, uma vez que "[...] ele só adquire significado completo pelo contexto sempre crescente e mutável da estrutura conceitual em que se insere" (JAMMER, 2011, p. 22). Desse modo, ao investigar a construção de um constructo científico, é necessário atentar-se para a inevitável imprecisão do mesmo e para o perigo que é traçar limites, temporais ou teóricos, estreitos ou extensos demais.

Poincaré (1905, p. 91-92, tradução nossa), em sua clássica obra A ciência e a hipótese, ao discutir sobre a lei da inércia, escreve sobre a questão das forças (ou nãoforças) e como o professor as interpreta:

Já houve experimentos em corpos onde não agiam forças? E, em caso afirmativo, como saberíamos que nenhuma força estava agindo? O exemplo comum é o de uma bola rolando por muito tempo sobre uma mesa de mármore; porém, por que dizemos que está sob a ação de nenhuma força? É porque está muito distante de todos os outros corpos para experimentar qualquer ação sensata? Não está mais longe da Terra do que se fosse jogado livremente no ar; e todos nós sabemos que, nesse caso, estaria sujeito à atração da Terra. Os professores de Mecânica costumam passar rapidamente pelo exemplo da bola, mas acrescentam que o princípio da inércia se verifica indiretamente por suas consequências. Isso está muito mal expresso; eles evidentemente querem dizer que várias consequências podem ser verificadas por um princípio mais geral onde a inércia é apenas um caso particular. (POINCARÉ, 1905, p. 91-92).

Entende-se que o princípio da inércia é um dos fundamentos para a compreensão de uma nova Mecânica que por séculos a fio tentava mudar a descrição dinâmica da antiperistasis aristotélica ou, cessante causa, cessat effectus, mas que precisou ser refinada desde Philopponus no século VII a.E.C. até os nominalistas franceses Oresme e Buridan (século XIV), Bruno (século XVI) e Galileu e Descartes (século XVII), antes de ganhar os conceitos e axiomas de Newton em seus Princípios matemáticos da filosofia natural, além de seu systemata mundi com a força gravitacional (NEVES, 2000). 
Diante do exposto, ainda assim se considera que o conceito de força assume uma posição ímpar entre os demais conceitos físicos, e o seu desenvolvimento histórico pode revelar como ocorreu a mudança da atitude intelectual dos cientistas ao longo dos tempos, bem como pode corroborar para que o seu ensino seja contextualizado e desvinculado de concepções equivocadas, distorcidas e superestimadas. Nessa perspectiva, este trabalho objetiva compreender como os conceitos de força nos séculos XVII e XVIII são manifestos nas falas de professores universitários de uma instituição pública do estado do Paraná.

\section{Breve Histórico de Conceitos de Força nos Séculos XVII e XVIII}

O desenvolvimento histórico dos conceitos de força inerentes aos séculos XVII e XVIII não se deram de forma linear e cumulativa, pois os cientistas desse contexto, influenciados pelo meio científico e social que os cercavam, empenharam-se em construir teorias que explicassem como se dava a interação entre os corpos - por contato ou à distância. As interações físicas consistiam em um problema que permeava a mente dos estudiosos e os faziam elaborar teorias alicerçadas em ferramentas matemáticas e conceituais das quais dispunham na época.

René Descartes (1596-1650), filósofo, matemático e físico francês, em suas obras O mundo ou tratado da luz (2009) e Princípios da filosofia (2007), renunciou o conceito de força de sua física e aderiu exclusivamente às concepções matemáticas, rejeitando veementemente a ação à distância e a existência do vazio. Sua teoria dos vórtices buscou explicar os movimentos celestes e a gravitação.

A gênese do conceito de força pode ser encontrada na publicação dos Princípios matemáticos da filosofia natural, em 1687, pelo célebre físico Isaac Newton (16421727). Tal obra, também conhecido como Principia: "[...] foi um dos mais notáveis acontecimentos em toda a história da Física. Neles se encontram sintetizados milhares de anos de luta pela compreensão do sistema de mundo, dos princípios de força e movimento e da física dos corpos que se movem em meios diferentes." (COHEN, 1967, p. 159).

Newton, nos Principia, concebeu a existência de três tipos de força: a inata, a impressa e a centrípeta, bem como postulou as três leis do movimento, vinculadas às forças conjecturadas. A ação à distância foi, no princípio, revogada, porém no decorrer dos seus estudos passou a ser reconsiderada. (NEWTON, 2016).

Nas palavras de Ellis (1965, p. 31) "[...] a característica distintiva das forças em geral é que, em certo sentido, sua existência implica e é acarretada pela existência dos efeitos que se supõe que produzam". Nesse sentido, as leis do movimento referem-se a leis da dinâmica e sobre estas Ellis (1965) propôs que eram de origem conceitual e foram derivadas diretamente da física cartesiana e não da cinemática galileana. Ademais, o autor ainda afirma que a única evidência experimental, que foi de alguma forma foi essencialmente relevante para a verdade das leis de Newton, foi o ímpeto que Descartes e Huyghens apoiaram suas leis da conservação do momento (ELLIS, 1965).

A conceituação das forças assumiu uma posição ímpar na dinâmica euleriana, culminando na formulação da expressão matemática $F=m . a(E U L E R, 1752)$. Além dessa contribuição, Leonhard Euler (1707-1783) empenhou-se em compreender a origem das 
forças sob a perspectiva da impenetrabilidade da matéria. Euler, exímio matemático que foi, provavelmente percebia que não era necessário compreender a origem das forças para dar sequência aos seus estudos sobre o movimento, pois as leis que o regem podem ser descritas independentemente deste conhecimento. Contudo, Euler era adepto da tradição da filosofia natural, portanto, para ele, a razão carece "[...] conhecer as causas de todos os fenômenos e, mais especificamente, desse agente do movimento que é a força. Se, do ponto de vista matemático, ele pode dispensar esse conhecimento, do ponto de vista do saber, em geral, ele não o pode!" (EVANGELISTA, 2014, p. 63).

Já no século XVIII, o físico, matemático, astrônomo, padre e filósofo Roger Joseph Boscovich (1711-1787) desenvolveu trabalhos em diferentes áreas de atuação. Em particular na Física, buscou compreender o caráter geral da força e entender com precisão a lei que a regia, fazendo uso de representações gráficas com o propósito de melhor explicar sua teoria dinâmica das forças, que pautava-se na proposição de forças atrativas e repulsivas atuando entre as partículas de matéria, mantendo uma relação de dependência com a distância que as separavam (BOSCOVICH, 1922).

Ao caminhar para o término do século XVIII, a teoria dos fluidos imponderáveis buscou elucidar como ocorriam os fenômenos elétricos, magnéticos, térmicos e afins. Friedrich Wilhelm Joseph Schelling (1775-1854), como um dos principais representantes de um outro movimento teórico, conhecido como escola filosófica da Naturphilosophie, era adepto de uma física especulativa, dotada de uma concepção dinâmica da natureza, em que esta passou a ser expressa em termos de produto e produtividade, causa e fim dos fenômenos, opondo-se à concepção mecanicista, que julgava a natureza como uma máquina suscetível à obediência de determinadas ordens (SCHELLING, 2015). Findando o século XVIII, o programa de pesquisa laplaciano dedicou-se a explicar os fenômenos terrestres e celestiais, em particular na escala molecular, em termos de forças centrais entre partículas que poderiam ser consideradas atrativas ou repulsivas.

\section{Encaminhamentos Metodológicos}

A fim de atender ao objetivo da investigação, foram adotados os pressupostos metodológicos da pesquisa fenomenológica. Nesse sentido, para estudar o fenômeno e buscar compreendê-lo, é necessário"[...] ir-à-coisa-mesma tal como ela se manifesta, prescindindo de pressupostos teóricos e de um método de investigação que, por si, conduza à verdade" (BICUDO, 2000, p. 71). Para tanto, o pesquisador fenomenológico precisa ir ao encontro dos sujeitos de pesquisa, a fim de situar e contextualizar o fenômeno, uma vez que somente é possível observar as "coisas mesmas" a partir do instante em que elas se manifestam para o sujeito que as interroga.

Os sujeitos da pesquisa foram cinco professores de Física de uma universidade pública do estado do Paraná. Como critérios, optou-se por dar preferência aos docentes que ministram ou já ministraram aulas de física básica para o curso de Física na referida instituição, ou que possuíam um vínculo com o ensino de Física. Ressalta-se que foi preservada a identidade da instituição de ensino, bem como a dos sujeitos, de modo a atender as exigências do Conselho de Ética institucional.

De modo a contextualizar os participantes da pesquisa, destaca-se que o participante 1 da pesquisa é licenciado e bacharelado em Física, possui mestrado 
e doutorado em Educação para a Ciência e a Matemática e mais de nove anos de experiência no Ensino Superior; o participante 2 é graduado em Física, mestre e doutor em Física, com 25 anos de docência no Ensino Superior; o participante 3 é licenciado em Física, possui mestrado em Físico-Químico e doutorado em Física, tem experiência profissional de aproximadamente 37 anos, sendo a grande maioria no Ensino Superior; o participante 4 é bacharel, mestre e doutor em Física e atua há nove anos no Ensino Superior; o participante 5 também é bacharel, mestre e doutor em Física, com 31 anos de experiência enquanto docente do Ensino Médio e Superior.

A interrogação fenomenológica voltada para o retorno "à-coisa-mesma", livre de pressupostos e julgamentos constitui-se a époche, que significa "[...] dar um passo atrás e parar com as formas familiares e comuns de olhar as coisas, as quais impedem que sejam vistas" (MARTINS; BICUDO, 1983, p. 12). Este rigor fenomenológico permite ao fenômeno mostrar-se nas multiplicidades de suas formas.

Com o propósito de ir à-coisa-mesma e não a conceitos ou a ideias que tratem a respeito, "[...] é preciso irmos ao sujeito que percebe e perguntarmos o que faz sentido para ele, tendo como meta a compreensão do fenômeno investigado. O sujeito expõe aquilo que faz sentido, ou seja, ele relata, descreve o percebido" (BICUDO, 2000, p. 74). Nessa perspectiva, tendo em vista que o objetivo da pesquisa é compreender como os conceitos de força nos séculos XVII e XVIII são manifestos nas falas de professores universitários de uma instituição pública do estado do Paraná, a indagação feita aos interlocutores da investigação foi: como você acredita que se deu a construção da noção do conceito de força?

A pergunta proposta apresenta-se de forma aberta e abrangente e a essa questão "[...] podem se seguir outras, desde que relacionadas com o tema pesquisado e com as respostas dadas pelos participantes" (MARTINS; BICUDO, 1989, p. 32).

As entrevistas com os sujeitos da pesquisa foram filmadas e transcritas a fim de que fosse possível o início das descrições das mesmas. Para ajudar na análise das descrições, Martins e Bicudo (1989) sugerem que, incialmente, estas sejam lidas na íntegra, visando familiarizar-se com o texto que descreve a experiência vivida. A análise das descrições é, portanto, uma operação que "[...] visa o sentido do dito buscando na totalidade do descrito nesse depoimento individual e os significados que o transcendem, uma vez que estão articulados às expressões culturais de sentidos percebidos e trabalhados pelos atos da consciência" (BICUDO, 2011, p. 56-57).

Após a leitura atenta do descrito em sua totalidade, as descrições foram relidas, quantas vezes foram necessárias, a fim de descartar os discursos considerados ingênuos. Já os trechos que comportam essencialidades são extraídos e, dessa forma, emergem as Unidades de Significados, que por sua vez "[...] podem revelar as essências dos fenômenos postos em questão" (NEVES, 2005, p. 51). Posteriormente à identificação das mesmas, buscou-se compreendê-las individualmente, bem como se procurou transformar as expressões empregadas pelos interlocutores em uma linguagem psicológica, cuja denominação atribuída por Neves (2005) é "compreensão da situação relatada na unidade".

Na sequência, efetuou-se a compreensão ideográfica, na qual o pesquisador fenomenológico analisa e interpreta os discursos individualmente, buscando "[...] resgatar de cada conjunto de unidades uma inteligibilidade do indivíduo" (NEVES, 2005, p. 53). Trata-se "[...] da análise da ideologia que permeia as descrições ingênuas 
do sujeito. A raiz do termo está em ideografia, que se refere à representação de ideias [...]" (MARTINS; BICUDO, 1989, p. 100, grifo dos autores).

Após o término das representações ideográficas, que apresentam as estruturas de cada indivíduo, pretendeu-se chegar às categorias, bem como revelar as convergências presentes nos discursos dos sujeitos. Esse procedimento é denominado de Compreensão Nomotética, e tem como objetivo chegar a uma estrutura geral psicológica. Segundo Martins e Bicudo (1989, p. 106) "[...]esse empreendimento envolve uma compreensão dos diversos casos individuais com exemplos de algo mais geral e a articulação desses casos individuais, como exemplos particulares, em algo mais geral".

A análise nomotética transcende o aspecto individual da análise ideográfica e caminha em direção a uma interpretação mais abrangente em termos de categorias abertas. Esse empreendimento demanda comparações entre as estruturas psicológicas obtidas individualmente, buscando identificar convergências e divergências. Esta etapa interpretativa requer insights, a fim de auxiliar na compreensão dos casos individuais como exemplos particulares, em algo mais geral. Contudo, é válido sinalizar que a análise nomotética não é somente a verificação cruzada de correspondências e afirmações reais, mas sim "[...] significa que ela é a ação profundamente reflexiva sobre a estrutura psicológica à luz de outras descrições para encontrar aspectos comuns que estão algumas vezes implícitos" (MARTINS; BICUDO, 1989, p. 109).

Após definidas as categorias, se buscou realizar a compreensão eidética das mesmas, cuja preocupação se concentrou em analisar as convergências existentes em cada categoria. De acordo com Martins e Bicudo (1989, p. 77) "[...] compreender eideticamente significa tomar o fenômeno seriamente diante dos olhos e estudálo de maneira sistemática para poder vir a compreender o objeto na sua intenção total, na sua essência, e não apenas na sua representação". Por fim, buscou-se chegar à compreensão nomotética geral, uma análise mais ampla e abrangente relativa ao fenômeno investigado.

\section{Análise dos Resultados}

A partir do caminho trilhado à luz da pesquisa fenomenológica, foi possível encontrar quatro categorias, oriundas das interpretações das Unidades de Significado e das Compreensões Ideográficas. Contudo, em virtude do limite de páginas, serão apresentadas somente as Compreensões Eidéticas de cada categoria com alguns excertos das falas dos sujeitos de pesquisa, buscando reunir as convergências identificadas nos e entre os discursos dos participantes da pesquisa que, com efeito, propiciam compreender o fenômeno em sua essência e totalidade. Para a transcrição dos discursos foram utilizadas uma adaptação das normas de transcrição de entrevistas gravadas (PRETI, 1999).

\section{Compreensão Eidética das Convergências da Primeira Categoria: compreensão de conceitos de força}

Os sujeitos de pesquisa destoam em relação à profundidade em que discutem o conceito de força, mas assemelham-se quanto à definição em si. Os discursos mais 
concisos associam a força a uma alteração do estado de movimento de um objeto, enquanto que os mais rebuscados entendem a força como um agente físico responsável pela aceleração deste objeto.

Ah... basicamente força mecânica né...coisa de você empurrar, puxar, ter o básico para ele entender essa, essa relação da variação de velocidade com, com a existência de uma força, com uma resultante agindo sobre o corpo [Sujeito 1].

[...] o que você observa na natureza, que você tem dinâmica, os objetos se movimentam, eles não se movimentam por livre e espontânea vontade, tem que ter alguma coisa que induz esse movimento. Então para você descrever essa dinâmica, daí você usar várias formulações. Uma das formulações é você usar $F=m . a$, daí você faz toda aquela descrição de quando você tem um desequilíbrio de força e isso automaticamente induz a uma aceleração no objeto. Essa é a descrição mais simples, né, mas depois você pode introduzir isso como um gradiente do potencial né, então se você coloca um corpo sujeito a uma diferença de potencial, esse corpo vai tender a ir para uma região de menor potencial e isso equivale à força que ele sente né. Então daria para descrever talvez de uma maneira diferente, que nem eu falei, fazer uma descrição usando uma formulação newtoniana, onde você tem, o sistema newtoniano você tira as equações que vão descrever essa dinâmica via equação de Hamilton - Jacob ou... Lagrangiana, onde você tiraria a dinâmica via equação de... Lagrange, sem necessariamente escrever $F=m . a$. [...] o que se precisa é dada a dinâmica, você descrever a evolução, como que ocorre essa evolução, de uma forma precisa. Mas, sempre lembrando que tanto a formulação newtoniana $F=m$. a ou lagrangeana-newtoniana vai levar a mesma equação que vai descrever a dinâmica daquele corpo lá, isso é independente. São maneiras diferentes de formular um efeito físico, você observa um objeto que está em movimento e você pode matematicamente descrever de forma... diferente. [Sujeito 2].

Bom, o conceito de força, você sabe que é um conceito que tem uma longa história né, uma longa evolução conceitual, se a gente quiser, a gente começa é: desde a física Aristotélica né, em que a força era um ingrediente necessário para manter o movimento, é: normalmente, nas vezes em que eu tenho a chance de falar sobre isso e no curso de história da física a gente discute muito a evolução deste conceito, a ideia é passar, mostrar antes de mais nada de que se trata de um conceito intuitivo em algum, algum sentido, que depois foi sendo elaborado, né, ao longo da história, foi confundido muitas vezes com o conceito de vis, foi confundido muitas vezes com momento, com força mesmo, com energia né. Então quando eu estou ensinando eu começo com uma linguagem um pouco mais enxuta, operacional, quer dizer se você pega como exemplo a:: lei da dinâmica fundamental $F=m$.a, eu procuro enfatizar que a força é um agente físico responsável por aquele a que está ali, então eu detecto o a e atribuo a vizinhança do meu corpo a ação né, é... de um agente físico que promove essa aceleração. Mas, depois é::, naturalmente eu caminho em direção ao conceito de campo, pra falar, porque surge naturalmente no contexto, mesmo quando você ensina em mecânica ou quando está dando aula de física quântica e que esse conceito, ele muda completamente, quer dizer, a tendência da física moderna-moderníssima- é que o conceito de força se evapore, porque na relatividade/ a palavra é muito forte 'evaporar', ele não é mais necessário nos moldes antigos [...], então, é uma resposta longa, mas num primeiro momento eu acho conveniente fazer uma definição de força quase que operacional para, pra você introduzir, discuti-la em conexão com o conceito de massa, e tal, tirar as representações anímicas, né, força muscular, etc., pro aluno entender que agora nós estamos falando é:: de um agente físico que atua no sentido de mudar o estado de movimento do corpo. [Sujeito 3].

Depois de muitas vezes ficando olhando para esse tipo de coisa e tentando usar um argumento unificado, eu tento falar que força é o efeito do resto do universo sobre uma partícula. O que que eu quero dizer é assim, eu considero uma partícula, olhando para uma partícula, o que que é força? É o efeito do resto do universo sobre a partícula. Esse efeito aí ele é definido meio quantitativo né, aí se for definido dinâmico né, é:: massa vezes aceleração igual a força $(F=m . a)$. Então, quer dizer, só fica definido quando escreve a expressão matemática, né, se a massa for constante como eu disse é massa vezes aceleração igual a força e qualitativamente representa o efeito do resto do universo sobre a partícula, do ponto de vista do movimento dela né, é só isso. [Sujeito 5]. 
Há enunciados mais abrangentes em que a força diz respeito ao resultado da interação entre corpos, que demandaram e ainda demandam muito empenho para se compreender como ocorrem, dependendo do período histórico e do campo de pesquisa. Há também sentenças em que o sujeito faz uso de um argumento unificador, em que a força é concebida como o efeito do resto do universo sobre uma partícula. Desse modo, tem-se um escudo que o protege de eventuais problemas conceituais.

Aparentemente, para os Sujeitos, a expressão conhecida como segunda Lei de Newton, $\mathrm{F}=\mathrm{m} . \mathrm{a}$, apesar de não ter sido proposta por este, descreve satisfatoriamente a dinâmica de uma partícula. Para sistemas mais complexos, é imprescindível valer-se de formulações oriundas da mecânica clássica, da relatividade e da mecânica quântica para prever os efeitos físicos decorrentes. Nesse contexto, a força assume um caráter relacional.

Ellis (1965) pontua que a conhecida segunda lei de Newton originalmente proposta podia ser considerada a definicional de força, erigida sobre o preceito de que uma causa é proporcional ao seu efeito (atualmente, porém, tem-se um esquema conceitual diferente, pois a ideia de força instantânea é um conceito fundamental de força dinâmica e impulso é um conceito definido). Contudo, na perspectiva de Poincaré (1905), os princípios da dinâmica em princípio apresentam-se como verdades experimentais, mas posteriormente estes passaram a ser usados como definições e por definição a força é igual ao produto da massa pela aceleração e este é um fundamento que está fora do alcance de qualquer experimento futuro e, portanto, desprovidos de qualquer significado.

Ao se debruçar sobre os discursos dos sujeitos, apreende-se que, de modo geral, ora concebem a força numa perspectiva peripatética tradicional, como uma "tendência" ou um "esforço para", e ora a uma concepção newtoniana, relacionada à causalidade, em que o movimento é um efeito e a força (impressa), a causa (JAMMER, 2011).

Ao considerar que a força é a causa do movimento, Poincaré (1905) afirma que se está falando de metafísica e se contentar com esta definição seria absolutamente infrutífero, visto que para que uma definição tenha alguma utilidade, ela deve informar como medir a força e isso é bastante suficiente, pois não é necessário dizer que a força existe em si mesma, nem se é a causa ou o efeito do movimento, mas sim deve-se primeiro definir o que significa igualdade de duas forças.

De maneira genérica, também é possível inferir que a conceituação de força assenta-se essencialmente nas três leis de Newton, mesmo que a sua segunda lei do movimento não corresponda à expressão $\mathrm{F}=\mathrm{m}$.a. Todavia, o intuito deste ensaio não é, naturalmente, minimizar os feitos de Newton, uma vez que, desde sua época, nenhum princípio essencialmente novo foi declarado, pois o que foi realizado posteriormente refere-se a um desenvolvimento dedutivo, formal e matemático da Mecânica com base nas suas leis (MACH, 1919).

\section{Compreensão Eidética das Convergências na Segunda Categoria: construção do conceito de força}

Em relação à construção do conceito de força, foram obtidas respostas bem rudimentares, com exceção do discurso proveniente do Sujeito 3, indicativos de 
prováveis desconhecimentos ou esquecimentos sobre o tema. Também é presumível que os sujeitos não tenham interesse ou não sintam necessidade de compreender a história do conceito que usam e ensinam com considerável frequência, tendo em vista que:

Reconhecidamente, o estudo dos aspectos históricos da geração de conceitos da física não é uma tarefa simples. Além de rigorosa formação histórica e filológica, necessária ao domínio habilidoso de material original, ele exige a compreensão da teoria física para que se possa comparar e interpretar criticamente as fontes em debate e avaliar seu significado para a ciência como um todo. (JAMMER, 2011, p. 21).

O conceito de força teve origem, na perspectiva da maioria dos sujeitos, a partir dos estudos sobre o movimento dos corpos. Para o Sujeito 1, essas investigações têm início com Aristóteles; para os Sujeitos 2 e 4, originam-se da experiência diária das pessoas, e para o Sujeito 5 tiveram início com os antigos pensadores -sem, no entanto, mencioná-los- até chegar em Newton.

Ah... Aívocê me pegou, faz muito tempo que eu fiz o curso de história da física. Isso começa a tentar entender o:: movimento em si, não é, desde o::/ talvez de destaque é... comece a se pensar nisso mais pesadamente a partir dos estudos de Aristóteles, mas tudo se dá em relação ao estudo do movimento, lógico que, é... antigamente o conhecimento que eles tinham, os recursos que eles tinham era muito precários né, tanto que se demorou muito tempo até alguém realmente quiser fazer um experimento, desses imaginários de se falar [...] de tentar fazer e mostrar o que acontecia, então é... eu acho que a construção tem que se [...], basicamente que se for trabalhar, especificamente o conceito de força, deveria se começar com o que os antigos pensavam e como isso foi evoluindo até chegar nas construções, vamos dizer assim, mais adequadas, a partir de Galileu [...] [Sujeito 1].

Eu acho que pela própria experiência diária que as pessoas tinham, isso... você vê que consegue fazer objetos se movimentar mais rápido ou mais devagar. Então eu acho que isso vem da própria experiência do ser humano. O conceito de força, para mim, é uma coisa que é natural desde os primórdios... O ser humano entende o que significa fazer uma força sobre um objeto e aquilo lá automaticamente resulte algum tipo de movimento. Agora você fazer a descrição matemática que que é uma coisa que veio com o desenvolvimento da matemática e pessoas que conseguiram fazer a formulação certa. O conceito em si de força para mim é uma coisa quase que natural, da experiência do dia-a-dia que a pessoa tem. Acho que uma criança entende o conceito de força em si, o que significa, se fazer força e a consequência disso. [Sujeito 2].

Então, mas a história, ela é longa e ela é complicada porque num primeiro momento, por exemplo, vamos começar com Aristóteles, né, vamos pegar um grande tratado, a gente poderia fazer isso até antes, nos pré-socráticos, então, mas a coisa não é... é muito, é muito difícil reconhecer e é perigoso a gente, é... perigoso do ponto de vista metodológico né? você colocar sua cabeça moderna ou pósmoderna lendo esses escritos, agora em Aristóteles, né. Nos livros de física e sobretudo no livro de física mesmo é:: existe um conceito de força que não é o nosso, evidentemente, mas é um esforço pra associá-la ao movimento do corpo, mas ali a força e o movimento do corpo estão implicados né, então a evolução desse conceito, ela parte de algo que é inerente ao próprio corpo como se o corpo estivesse implicado no movimento até atingir a quase que não necessidade, em Descartes, Descartes faz uma Física de precursão, quer dizer, toda a interação é basicamente por contato né, olha já estou usando um conceito moderno: o conceito de interação, porque não é simples, pelo menos eu não acho, separar metodologicamente né, é.. o conceito de força mesmo, aí ele vai adquirir um caráter é:: realmente mais bem definido, digamos na, na síntese newtoniana, então todo esse período da revolução científica, pra depois finalmente adquirir um conceito relacional né, se você quiser a gente pode, mas você não pode 
fazer isso num curso básico, chegar até a discussão de Mach e de uma mecânica onde a força possa aparecer realmente como algo relacional. A gente não faz isso porque... talvez não seja necessário para a formação do estudante num primeiro momento, quer dizer, é:: eu volto a insistir é.., você discute sim o conceito tentando dizer que é preciso desentranha-lo desde a antiguidade, onde ele vinha confundido, como eu te disse foi confundido com momento até se entender o momento e aí vê-lo como responsável pela variação do momento ou da quantidade de movimento com o tempo, mas eu vou/ até em Leibniz, por exemplo, algumas vezes esse conceito de vis, ele que usou muito o conceito de vis viva, a energia cinética, mas algumas vezes, dava a entender que era uma quantidade escalar, aí você pensava 'bom, deve ser energia, ele tá pensando em energia', mas às vezes, era uma quantidade vetorial, aí dava a entender que estava pensando em uma variação de quantidade de movimento, né. Então, a evolução é lenta, até termos a partir da segunda lei, das leis de Newton de modo geral né, é:: segunda e terceira, que tratam mais diretamente da/ é:: a possibilidade de introduzir definições, com as quais você opera, então eu acho que fazer essa passagem de um conceito que é quase que animístico, implicado no corpo, para um conceito em torno do qual você pode operar, definir a partir de uma balança, comparar as ações dessas, sobre dois corpos de massas diferentes e as duas coisas vêm juntas de novo né, você sabe que esse conceito ali no Principia eles estão é:: não é que eles estão implicados no sentido de que eles não são claros, mas é que eles se tornam claros na medida em que você introduz os dois né, essa ideia né, não sei se eu respondi... essa é minha ideia. E eu gosto sempre de trazer, mesmo nas poucas vezes que dei o curso de Física l e sobretudo nos de história da física mesmo de mecânica quântica, trazer a problemática para a física contemporânea porque a gente consegue olhar retrospectivamente como foi difícil fazer esse, esse percurso para entender a interação entre dois corpos, porque no fundo é disso que se trata, dois corpos, um corpo pode ser o meu, um corpo $m$ aqui e o resto... do universo né, o ambiente todo ou dois corpos mesmo que é suficiente, eu preciso ter duas instâncias assim que interajam, né. É depois [...] vai ter o conceito de auto interação, que é uma coisa mais elaborada em eletrodinâmica quântica, é:: então para não confundir, quando você é:: explica é:: insistindo e explica para um estudante, pra gente mesmo né, insistir em distingui-la de momento, de trabalho, de esforço né e tentar limpar esse conceito para dar a ele uma definição com a qual se opera, uma vez que você tem essa definição com a qual se opera você passa por um conceito de interação, pro conceito de campo e aí eu acho que você consegue colocá-lo numa perspectiva mais ampla. É mais ou menos isso... [Sujeito 3].

Ah... eu não faço ideia assim, eu acho que aí você fala mais no sentido epistemológico? Eu acho que a noção do conceito é o de movimentar coisas assim né, o quanto de:: força necessário para um objeto mudar seu estado de movimento. Eu acho que surgiu nesse aspecto assim né. Você vê que a pessoa ela, ela precisava fazer uma certa atividade e essa atividade demandava uma certa força que ela teria que ter para fazer. Então, eu acho que tá nesse conceito aí. [Sujeito 4].

Nota-se um aparente salto conceitual, desde Aristóteles ou dos filósofos antigos até as contribuições mais recentes de Galileu e de Newton, principalmente. Contudo, em relação à Galileu, vale ressaltar que em suas obras o mesmo não se comprometeu com nenhum sistema dinâmico particular, seus estudos eram voltados à cinemática (ELLIS, 1965). Digno de comentário é seu princípio errôneo de uma inércia circular, que nada tem a ver com as ideias de Descartes e Newton que se seguiriam. Pontuase também a insinuação de que o conceito de força se desenvolveu naturalmente ou intuitivamente, desconsidera-se ou desconhece-se, portanto, o minucioso e importante trabalho realizado por cientistas, escolas filosóficas e programas de pesquisa. Um caminho que repete a noção irreal de evolução das ideias, e não de especialização das ideias. Um exemplo podemos ver em Toulmin (1982, p. 45-46):

O fato é que Aristóteles baseava suas análises sobre um conceito particular ou paradigma explicativo, que ele formulou tomando em consideração exemplos correntes da natureza; ele usava estes exemplos como objetos de confronto para procurar entender e explicar qualquer tipo de movimento. Se se quer compreender 
o movimento de um corpo (segundo o seu ponto de vista) dever-se-ia pensar nesse em termos do movimento de um cavalo e de uma carroça: dever-se-ia, isto é, procurar dois fatores - o fator externo (o cavalo) que tem o corpo (a carroça) em movimento, e a resistência (a aspereza da estrada, o atrito da carroça) que tendem a parar o movimento. Explicar o fenômeno significa reconhecer que o corpo está se movendo à velocidade adequada a um objeto de seu peso, quando está sujeito àquele particular equilíbrio de força e de resistência. É natural, portanto, atentar, em condições de equilíbrio entre ação e resistência, para o movimento constante do corpo. Resultará, então, explicado qualquer fato que exemplifique este equilíbrio.

Com respeito a essa questão, o Sujeito 3 disserta sobre como se deu a construção do conceito de força, desde os pré-socráticos até as proposições mais recentes inerentes à mecânica clássica e a mecânica quântica. Sua fala transita pela concepção de força como esforço muscular, como uma representação animística e estende-se a uma atividade intrínseca que provocava o movimento - o ímpeto. A explanação vai além e situa a força no contexto newtoniano, como um agente físico sujeito a regras matemáticas, que Ihe dão credibilidade metodológica e técnica. Na sequência, o Sujeito 3 centra sua explanação nos séculos XVII e XVIII, e concede a Euler o devido destaque pelo desenvolvimento de um primoroso trabalho, não somente no que se refere à proposição de $\mathrm{F}=\mathrm{m} . \mathrm{a}$, mas sobretudo na matematização e aperfeiçoamento da dinâmica newtoniana.

Percebe-se, portanto, que dentre os indivíduos entrevistados, somente o Sujeito 3 demostra compreender como se deu a construção do conceito de força, em especial no século XVII e XVIII. Nesse sentido, apreende-se que, enquanto docente, o referido sujeito terá muito mais a contribuir na formação histórica e conceitual de seus alunos, futuros professores de física.

\section{Compreensão Eidética das Convergências da Terceira Categoria: força como um conceito intuitivo}

O conceito de força, em linhas gerais, é percebido como intuitivo. Para os Sujeitos 2 e 4, desde a infância as crianças entendem o que é força, visto que, contemplam-na diariamente em situações corriqueiras de movimento de objetos. Na perspectiva do Sujeito 3 (como evidenciado em fala anterior), em algum sentido o conceito é intuitivo, porém precisou ser elaborado do decorrer na história, uma vez que comumente era confundido com outras definições, como momento e energia.

O conceito de força sim porque até uma criança entende isso. Você fala, dá uma força aqui, que nem diz o outro ou faz uma força para movimentar aquele objeto, a criança vai lá e faz. O que não é intuitivo é a notação vetorial que você precisa para descrever essa dinâmica né, porque força é um vetor, vetor é, como você adiciona vetor, subtrai vetor como você manipula vetores já é uma coisa que você precisa ter um embasamento, que já não é tão intuitivo, mas o conceito de força eu acho que é... qualquer criança consegue entender, você consegue explicar. [Sujeito 2].

[...] eu acho, na verdade, que eles já vêm com uma concepção do que é força. Eu acho que, desde criança a gente aprende essa concepção do que é força, só que, eu não sei exatamente se a gente sabe esse conceito de maneira correta ou não. Mas eu acho que intuitivamente eles têm esse conceito na cabeça. [Sujeito 4].

O Sujeito 5, por sua vez, levanta pertinentes apontamentos referentes à aproximação entre intuição e costume. Nesse sentido, o conceito de força é concebido 
como intuitivo, na medida em que uma determinada sociedade está familiarizada com este termo e suas aplicações, caso contrário, tal constructo deixa de ser intuitivo.

\begin{abstract}
Demorou muito tempo para ficar intuitivo pra mim [risos]. Essas coisas de intuitivo eu acho meio curioso, o que que é intuitivo ou não, eu acredito que o conceito de força tem um alto conteúdo de intuitivo, mas quando meche com física, deve ficar quantitativo entre a intuição e a definição quantitativa tem uma distância fabulosa, assim por exemplo, é, vou dar exemplo pra você. Vários povos indígenas, separados uns dos outros, eles têm uma noção sobre as constelações e muitas vezes, grandes partes das constelações são idênticas, mesmo não conhecendo um ou outro, então por exemplo, hoje um monte de pessoas ficam falando de terra plana né, eu acho que a ideia de terra plana é um dos primeiros conceitos que as pessoas pensam né e o conceito de força é em certo grau, aí depende muito de como que foi o meio que a pessoa né está imerso né, mas o conceito de força é em certo grau intuitivo, mas se você pensa por exemplo lá que os gregos ficaram um tempo imenso certo, sem ter uma definição mais clara do que é força, você fala é, não é tão intuitivo né, entendeu? Então é uma situação assim muito curiosa, o que que é intuitivo ou não né. [Sujeito 5].
\end{abstract}

Repetindo Poincaré (1905), reitera-se que a ideia de força é primitiva e, portanto, as pessoas possuem uma intuição direta, que surge da ideia de esforço que é familiar desde a infância. Contudo, em primeiro lugar, mesmo que essa intuição possibilitasse conhecer a natureza real da força em si, ela se revelaria uma base insuficiente para a mecânica e inútil, pois, para o autor o importante não é saber o que é força, mas sim como medi-la.

Compreende-se que postular que o conceito de força é intuito pode trazer implicações negativas para o seu ensino, pois se o professor partir desse pressuposto, é provável que ele não designe muito tempo a sua explicação, contextualização e reconstrução histórica.

Assume-se neste trabalho que a força é uma mediadora da interação entre os corpos. Sendo assim, é válido questionar se a maneira como se dá essa interação é intuitiva? Para responder tal indagação é necessário reportar-se ao percurso histórico pelo qual o conceito de força passou, para embasar-se teoricamente e poder afirmar categoricamente que o modo como se dá essa interação não foi e ainda não é intuitivo.

\title{
Compreensão Eidética das Convergências da Quarta Categoria: compreensão sobre a história da ciência
}

Ao versar sobre o conceito de força e sua construção, alguns sujeitos expuseram suas concepções acerca da História da Ciência e sua possível implementação no ensino. O Sujeito 1, por exemplo, vislumbra potencialidades, mas elenca uma série se empecilhos que tendem a inviabilizar sua efetiva implantação.

[...] É... eu não consigo e provavelmente nunca vou conseguir fazer uma atividade que envolva a história da Física, porque o tempo da disciplina não é grande, apesar da disciplina ser anual, a gente tem uma carga de trabalho muito grande, os alunos têm que ir pra escola.., não sei o quê. Pra trabalhar com a história da física é necessário muito conhecimento, muita leitura e a gente: até hoje eu não consegui incluir, é... realizar uma atividade de estágio envolvendo a história da física. Então eu nunca trabalhei com essa questão de eles discutirem algum tipo de conceito em si, somente algum recurso ou metodologia de como trabalhar aquele, aquele..., um conteúdo que normalmente eles são livres para escolher, mas nunca algo específico assim, um conceito de força, por exemplo, a noção de força, nunca algo tão específico. Potencialidade existe, é... só que, eu já discuti isso com muita gente, até mesmo com os próprios alunos, é... Há... uma 
noção errada, no meu modo de ver, sobre a abordagem dessa questão histórica, ah, tem que falar sobre a questão histórica, não sei o quê, é muito complicado fazer isso muitas vezes, como eu falei, é muita leitura, você tem determinados momentos que tem historiadores que têm visões diferentes, então você teria que discutir isso, porque senão você estaria só mostrando um lado, têm controvérsias, etc... [Sujeito 1].

Os Sujeitos 3 e 5 assinalam como foi difícil para os filósofos antigos e até mesmo para físicos como Newton e Euler compreender o conceito de força, suas causas e as equações que poderiam reger e prever o movimento dos corpos. O Sujeito 3 ainda discorre sobre as limitações e as objeções teóricas e matemáticas destes e dos demais cientistas.

[...] eu sempre me encantei por essa, essa é uma questão pessoal né, por essa física matemática do século XVIII, que é uma coisa maravilhosa que foi feita na história da humanidade né, e é um esforço gigantesco, é você fala 'poxa, um homem como o Euler, que não tinha dificuldade para entender nada, esse pessoal sofreu, como Newton sofreu e sofreu porque esses conceitos' e até eu vejo o esforço dos meus colegas que trabalham com a história da física e que vão mexer nos conceitos e tal, vão tentar entender porque esses conceitos da mecânica, eles são realmente muito difíceis para um homem comum e até para homens incomuns como esses que esses que a gente citou, quer dizer, muita gente tangenciou, você pega, vai estudar a Idade Média, onde você considera, por exemplo homens como Santo Tomás de Aquino..., muitas questões religiosas, um pensador profundista, um dos homens mais capazes que o ocidente já produziu né, uma das mentes pensantes mais rapazes, ou pegue um árabe como Averróis ou Avicena, esses homens tinham um poder especulativo imenso, bom, eles.. tangenciavam o problema do movimento e chegavam perto, mas não conseguiam dar um passo porque precisava romper com uma certa tradição de pensamento Aristotélico, é verdade, mas precisava também de um passo abstrato, de uma coragem que talvez eles não tivessem, mas a coragem não é 'coragem', coragem assim, um arroubo de pensamento né, que eles não estavam dispostos a dar, quer dizer, eu posso admitir um espaço porque a dinâmica para um filósofo da natureza, a dinâmica newtoniana e sobretudo a dinâmica de Euler colocada na forma grande da mecânica clássica [...] E aí você vê em homens como o Newton, Huygens né, Huygens principalmente, que também é supervalorizado aí antes de Newton. [...] [Sujeito 3].

[...] normalmente eu chamo atenção pros alunos é que demorou muito pra aparecer o conceito de força, então, várias... porque as três leis de Newton tiveram que ser juntadas né, muita gente não fala muito da terceira lei né, mas ela é essencial quando pensa em força, vários livros-texto não ficam falando tanto, ficam falando como uma propriedade, mas na hora de formular e juntar tudo é muito importante a terceira lei, mas então, voltando lá, naquela época foi trabalhoso, foi difícil, vou fazer um trocadilho: 'teve que fazer muita força pra chegar ao conceito de força', parece que depois que teve algum conceito assim com uma clareza com Newton, parece que já estava mais direcionado e que foi muito mais fácil outros desenvolvimentos e hoje a gente consegue resumir de alguma forma o conceito de força que foi aquele que eu comecei a conversa, em algum sentido, ele representa o efeito do resto do universo sobre uma partícula para um ponto de vista dinâmico e aí depois... porque é difícil né, porque é uma lei, é uma lei né, ela não sai de graça. [Sujeito 5].

Tais apontamentos vão ao encontro a uma visão de ciência aproblemática e ahistórica, que conjectura que:

[...] o fato de transmitir conhecimentos já elaborados, conduz muito frequentemente a ignorar quais foram os problemas que se pretendiam resolver, qual tem sido a evolução de ditos conhecimentos, as dificuldades encontradas etc., e mais ainda, a não ter em conta as limitações do conhecimento científico atual ou as perspectivas abertas. (CACHAPUZ et al., 2011, p. 47). 
O Sujeito 5 e, principalmente, o Sujeito 3 enfatizam a significativa influência que o contexto histórico e científico, manifesto por meio de escolas filosóficas e programas de pesquisa exercem nas proposições teóricas dos cientistas. Nesse sentido:

[...] é essencial compreender a ciência como um corpo de conhecimento historicamente em expansão e que uma teoria só pode ser adequadamente avaliada se for prestada a devida atenção ao seu contexto histórico. A avaliação da teoria está intimamente ligada às circunstâncias nas quais surge. (CHALMERS, 1993, p. 60).

Em relação à dualidade causa e efeito, o Sujeito 3 sinaliza que a física que está sendo praticada atualmente abandonou a busca por tal compreensão, pois enquanto operários de uma fábrica mercantilista, as pessoas, engenheiros e até mesmo físicos interessam-se apenas em operar e manipular dados e sistemas com o objetivo de propiciar o devido funcionamento de equipamentos. Contudo, ao voltar-se para o contexto dos estudantes do curso de licenciatura em Física, é pertinente refletir se é essa formação aplicacionista que se deseja oferecer, tendo em vista a futura área de atuação dos mesmos.

Em determinados momentos da sua fala, o Sujeito 5 exprime afirmações genéricas em que a História da Ciência é usada como forma de persuasão e intimidação. Nomes de cientistas e seus respectivos feitos são mencionados enfatizando uma concepção individualista e elitista da ciência. Nesses casos, de acordo com Martins (1990, p. 4) "[...] invoca-se a autoridade de um grande nome para reprimir dúvidas e impor doutrinas, invertendo assim a própria natureza do pensamento científico que, longe de se apoiar em nomes de autoridades, procura se basear em fatos e argumentos".

Nessa categoria, ainda é possível encontrar excertos em que a história da física ou a reconstrução histórica de um conceito como a força é concebida como ingênua, pois não vai corroborar para uma melhor compreensão do constructo. Todavia, em consonância com Martins (1990, p. 4):

Sob o ponto de vista da própria competência científica, a História da Ciência também pode dar contribuição. A própria compreensão dos resultados científicos mais complexos é virtualmente impossível, sem um conhecimento histórico [...]. Sem a História, não se pode também conhecer e ensinar a base, a fundamentação da Ciência, que é constituída por certos fatos e argumentos efetivamente observados, propostos e discutidos em certas épocas.

Diante do exposto depreende-se que os sujeitos apresentam distintas visões de ciência, sendo algumas mais adequadas que outras, dentro de uma variabilidade fenomênica parcializada que acaba eclipsando boa parte do fenômeno a quem se deveria dirigir a reflexão docente.

\section{Considerações Finais}

As falas que emergiram dos participantes da pesquisa, bem como os nãoditos, propiciam percepções notáveis e também preocupantes. Em linhas gerais, a construção de conceitos de força não alcança, como defende-se que deveria, o âmbito do Ensino Superior, tampouco o do Ensino Médio. A maioria dos professores, enquanto 
formadores de futuros licenciados em Física revelam desconhecimento deste arcabouço histórico ou o colocam como trivial, dispensável e irrisório, o que corrobora significativamente para que estes profissionais, quando estiverem em exercício de suas profissões, ensinem como foram ensinados, despojando-se de construções históricas essenciais para o entendimento de conceitos e valendo-se de encaminhamentos didáticos, metodológicos e epistemológicos reprodutivistas e reducionistas que simplificam o modo como os conhecimentos científicos são apresentados.

A concepção dos professores a respeito dos conceitos de força oscila; há sujeitos que os entendem como um conceito intuitivo e outros como não-intuitivo, há discursos que os consideram triviais e outros que os compreendem como complexos e, às vezes, não necessários com o advento da Física Moderna e da Relatividade. Pontua-se ainda que os manuais didáticos interferem na prática docente, às vezes de modo exclusivo e determinante, o que contribui para uma didática orientada para a resolução de problemas, bem como favorece a ausência de significação que assola boa parte dos conteúdos científicos. O conceito de força permanece latente na mente de alunos e professores, mas como um conceito abstrato e não ligado às situações empíricas do cotidiano, mas com variantes que vão além da cotidianidade do viver humano, e se projetam para toda a trama conceitual que vai da ideia da antiperistasis aristotélica às definições de força inercial e gravitacional em Newton e à cosmologia relativística de Einstein. Campos potencialmente abertos para a ciência e para o ensino das ciências.

\section{Referências}

BICUDO, M. A. V. A análise fenomenológica estrutural e variações interpretativas. In: BICUDO, M. A. V. (org.). Pesquisa qualitativa: segundo a visão fenomenológica. São Paulo: Cortez, 2011. p. 5374.

BICUDO, M. A. V. Fenomenologia: confronte e avanços. São Paulo: Cortez, 2000.

BOSCOVICH, R. J. A theory of natural philosophy: latin-english edition. Chicago: Open Court Publishing, 1922.

CACHAPUZ, A.; GIL-PEREZ, D.; CARVALHO, A. M. P.; PRAIA, J.; VILCHES, A. (org.). A necessária renovação no ensino de ciências. 3. ed. São Paulo: Cortez, 2011.

CHALMERS, A. F. O que é a ciência afinal? São Paulo: Brasiliense, 1993..

COHEN, I. B. O nascimento de uma nova física: de Copérnico a Newton. São Paulo: Edusp, 1967.

DESCARTES, R. O mundo ou tratado da luz. Campinas: Unicamp, 2009.

DESCARTES, R. Princípios da filosofia. São Paulo: Rideel, 2007.

ELLIS, B. The origin and nature of Newtons laws of motion. In: COLODNY, R. B, (ed.). Beyond the edge of certainty. Englewood, N.J., 1965. p. 29-67.

EULER, L. P. Découverte d'un nouveau principe de mécanique. Mémoires de l'Académie des Sciences, Berlin, v. 6, p. 185-217, 1752. Disponível em: https://scholarlycommons.pacific.edu/ euler-works/177/. Acesso em: 15 mar. 2021.

EVANGELISTA, L. R. Perspectivas em história da física: vol. 2. São Paulo: Livraria da Física, 2014.

JAMMER, M. Conceitos de força: estudos sobre os fundamentos da dinâmica. Rio de Janeiro: Contraponto, 2011. 
MACH, E. The science of mechanics: a critical and historical account of its development. Chigago: The Open Court Publishing, 1919.

MARTINS, J.; BICUDO, M. A. V. A pesquisa qualitativa em psicologia: fundamentos e recursos básicos. São Paulo: Morais, 1989.

MARTINS, J.; BICUDO, M. A. V. Estudos sobre existencialismo, fenomenologia e educação. São Paulo: Moraes, 1983.

MARTINS, R. A. Sobre o papel da história da ciência no ensino. Boletim da Sociedade Brasileira de História da Ciência, Rio de Janeiro, v. 9, p. 3-5, 1990.

NEVES, M. C. D. Uma investigação sobre a natureza do movimento ou sobre uma história para a noção do conceito de força. Revista Brasileira de Ensino de Física, São Paulo, v. 22, n. 4, p. 543-556, 2000.

NEVES, M. C. D. O que é isto, a ciência? Maringá: Eduem, 2005.

NEWTON, I. Principia: princípios matemáticos de filosofia natural: livro 1. 2.ed. São Paulo: Edusp, 2016.

POINCARÉ, H. Science and hypothesis. New York: Walter Scott Publishing, 1905.

PRETTI, D. O discurso oral culto. 2. ed. São Paulo: Humanistas, 1999.

SCHELLING, F. W. v. Schelling: aforismos para introdução à filosofia da natureza e aforismos sobre filosofia da natureza. São Paulo: Folha de São Paulo, 2015.

TOULMIN, S. Previsione e conoscenze: un'indagine sugli scopi della scienza. Roma: A. Armando, 1982. 